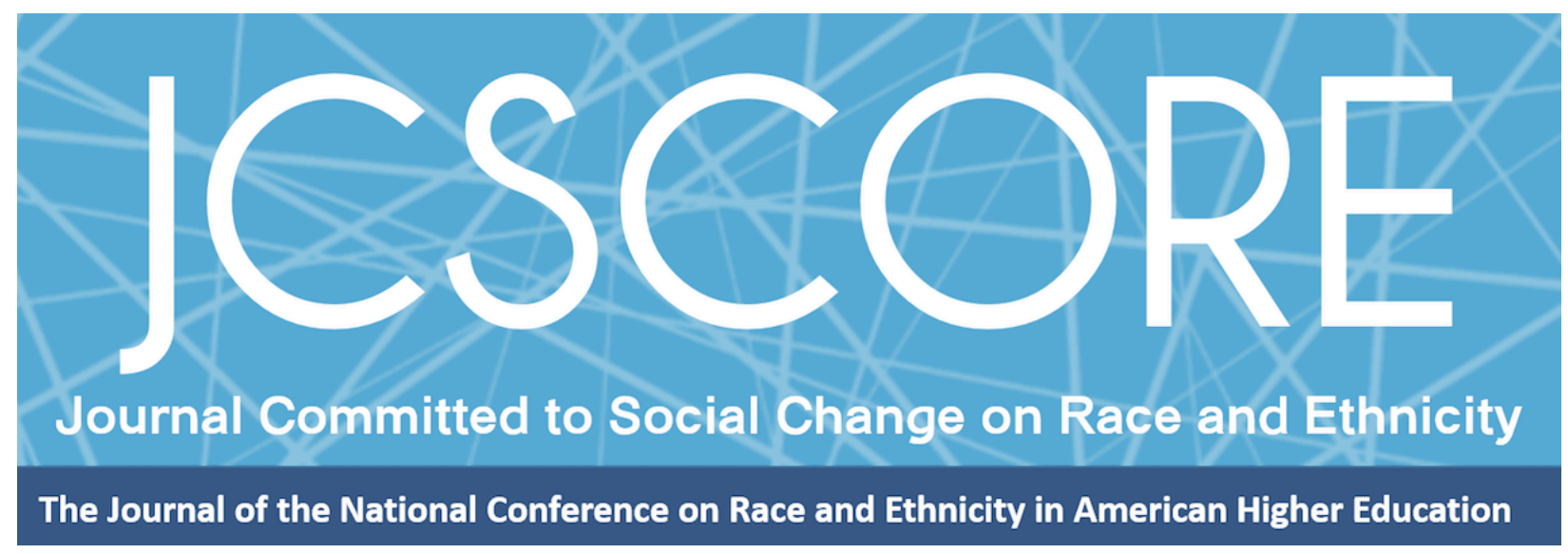

\title{
THE INFLUENCE OF WHITENESS ON THE GROUP SOCIALIZATION OF FRATERNITY MEN
}

\author{
S. Brian Joyce \\ Dartmouth College \\ Tony Cawthon \\ Clemson University
}

Journal Committed to Social Change on Race and Ethnicity

Volume 3, Issue 2 | 2017

Copyright (C 2017 Board of Regents of The University of Oklahoma on behalf of the Southwest Center for Human Relations Studies.

Permission of the Publisher is required for resale or distribution and for all derivative works, including compilations and translations. Quoting small sections of text is allowed as long as there is appropriate attribution. 


\title{
The Influence of Whiteness on The Group Socialization of Fraternity Men
}

\author{
S. Brian Joyce \\ Dartmouth College \\ Tony Cawthon \\ Clemson University
}

\begin{abstract}
This study was constructed as a qualitative analysis to understand how racial attitudes are socialized within members of traditionally White fraternities through a critical examination of participants' narratives on race. Narratives from seven participants were presented to identify five subcategories which were divided into two major themes for analysis: (a) Regulatory Behavior and (b) the Role of Racially Segregated Environments in Perpetuating White Supremacy. This study used institutional theory as a theoretical framework to deconstruct the ways in which Whiteness is perpetuated in hegemonic White spaces.
\end{abstract}

Traditionally, predominantly White fraternities have garnered negative reputations on many college and university campuses for discriminatory attitudes and behaviors. Specifically, fraternities were scrutinized for racist attitudes (Hughey, 2010; Muir, 1991; Patton, 2008). Increased media attention on recent racist incidents has brought racism in the college fraternity system to the forefront for educators and scholars (Associated Press, 2015).

Race and racial inequity are important topics on college campuses today because the college student population is more racially and ethnically diverse than ever. Schnoebelen (2013) reported in The Chronicle that college enrollment data indicated an increase in the number of underrepresented populations on campus. The number of Hispanic (a term used interchangeably in the cited article to refer to persons who identify as Mexican, Puerto Rican, Cuban, and/or Central and South American 
countries) students is projected to increase by 42 percent, Black students by 25 percent, Asian/Pacific Islander by 20 percent, and White students by only 4 percent. The demographics of American colleges and universities are quickly changing, thus impacting the country in which we live. As Pascarella, Edison, Nora, Hagedorn, and Terenzini (1996) suggested, "future college graduates will be challenged by a society that is increasingly diverse in terms of race, culture, and values" (p. 174).

Despite a changing demographic in colleges and universities, many traditionally White fraternities have remained largely homogeneous (Park, 2014). Recent qualitative narratives on racial attitudes in traditionally White fraternity members outlined a pattern of socialization in which fraternity members are indoctrinated with racialized stereotypes of students of color (Morgan, Zimmerman, Terrell, \& Marcotte, 2015). Additional research is needed to examine the impact that Whiteness has on in-group socialization of college men in a traditionally White fraternity as it pertains to race and racial attitudes.

The purpose of this study is to better understand how racial attitudes are socialized within members of traditionally White fraternities. The following questions guided our inquiry: 1) what is the salience of race for White fraternity men; and 2) how is Whiteness perpetuated in predominantly White settings. Hurtado, Milem, ClaytonPederson, and Allen (1999) suggested focusing diversity efforts on environments that perpetuated exclusion in the past to improve campus racial climates for the future. Focusing on privileged identities and those who control access to a powerfully influencing force in higher education can help guide student affairs and fraternity and sorority life professionals in better understanding the complex climate of race in a traditionally and predominantly White fraternity setting. 
Journal Committed to Social Change on Race and Ethnicity | 2017

\section{Campus Racial Environments and Fraternities}

Racial microaggressions have a significant effect on the experiences of students of color, while transforming the overall campus racial environment (Solorzano, Ceja, \& Yosso, 2000). While ranging from extremely hostile to slight, racial microaggressions are often more subtle than overt racism, making them difficult to identify and therefore challenging to address (Crocker \& Major, 1989). Students of color who experienced microaggressions reported feeling isolation, self-doubt, and frustration.

Microaggressions occurred in both academic and social spaces, causing many students of color to feel discouraged and unwanted in social situations, and discouraged many from seeking out these experiences (Solorzano et al., 2000).

White students often perceived increased racial tension on campuses with an increased enrollment of students of color (Hurtado, 1992). Students of color were even more likely to perceive prejudice and discrimination on campus (Cabrera \& Nora, 1994), but predominantly White campuses cultivated racial bias and even hate crimes for students of color (Van Dyke \& Tester, 2014). Traditionally White fraternities, in particular, were inextricably linked with racist incidents (Hughey, 2010; Muir, 1991; Patton, 2008).

The tendency to minimize racism and feelings of victimization from multiculturalism often go unchallenged when White students exist in racially segregated environments (Cabrera, 2014b; Sidanius, Van Larr, Levin, \& Sinclair, 2004). Traditionally White fraternities, in particular, created social comfort and insulated White men from overt racial conflict through the creation of White spaces. While White students reported experiencing harassment on college campuses, they experienced it at 
Journal Committed to Social Change on Race and Ethnicity | 2017

significantly lower rates and are often able to ignore it, a privilege not afforded to students of color (Rankin \& Reason, 2005).

The formation of predominantly White environments perpetuated by traditionally White fraternities were one of the two ways Cabrera (2014b) outlined how the traditionally White fraternity system recreated White supremacy in higher education. White men secluded themselves from interactions with peers of a different race (Cabrera, 2014b). Because they were protected from overt racial conflict, White men minimized racism in the college environment and even framed themselves as victims (Cabrera, 2014b).

The second way in which White supremacy was recreated was through the social comfort exhibited by being surrounded by other members of the same race (Cabrera, 2014b). The formation of environments where White students were surrounded almost exclusively by other White students normalized Whiteness and served to perpetuate views where White students saw little evidence of racism, strengthening skepticism about the racialized experiences of students of color (Harper \& Hurtado, 2007). Without regularly interacting with students of color, Whiteness and the White experience were normalized for many White students (Cabrera, 2012).

Many traditionally and predominantly White fraternities added White only membership clauses that formally restricted membership to White, Christian males in the early 1900s (Syrett, 2009). Barone (2014) explained that while some fraternities received pressure from alumni to remove the Whites only membership clauses in the 1950s, many eliminated the formal policies restricting membership access in their constitutions only to continue to subscribe to de facto discrimination. Historical records 
of fraternity convention meetings revealed that fraternity members formed gentlemen's agreements to form a public display of integration while denying membership to students of color in practice (Barone, 2014).

Harris (1993) discussed the concept of people of color "passing" as White, a feature of societies structured on White supremacy: "Becoming white meant gaining access to a whole set of public and private privileges (Harris, 1993, pg. 1713)." Traditionally and predominantly White fraternities have certainly provided access to networks, advantages, and privileges that have historically been afforded to White men only, and the White fraternity men involved shared common desires to exclude membership to protect those interests.

\section{Understanding Whiteness}

Exploring Whiteness is central to this study. Whiteness is a privileged social identity (Bonilla-Silva, 2001; Reason \& Evans, 2007). For the purposes of this text, Whiteness does not refer to White people, but rather an ideology of racial oppression and a way of protecting White supremacy (Cabrera, 2012).

Bonilla-Silva (2001) stated that White supremacy is maintained in United States culture through "the sophisticated racial practices of the new racism and the even more complex ideology of color blindness" (p. 199). These behaviors were difficult to address or disrupt because they were more covert and difficult to identify. Bonilla-Silva (2001) suggested that the next step in what can be done about this reality is developing new research agendas on White racial attitudes, specifically in exploring Whiteness from within. 
Journal Committed to Social Change on Race and Ethnicity | 2017

The behavior of White students within White spaces on college campuses is often vastly different when students of color are absent from the environment (Picca \& Feagin, 2007). Cabrera (2014a) analyzed 29 White student narratives on racial joking, which were almost always told in homogenous White environments. A consistent theme from the findings described jokes as simply humorous, not racist, and they were largely rationalized as harmless (Cabrera, 2014a). Because White students did not find racism in the jokes, those who did were overreacting and overly sensitive (Cabrera, 2014a).

Understanding the ways in which individuals of privileged identities reacted and understood privilege is important to unpacking it in a particular setting like higher education. Privilege can be difficult to acknowledge, and even more of a challenge to deconstruct within one's identity. Watt (2007) developed the privileged identities exploration model (PIE) as an explanation of typical responses associated with privileged identity development. The model identified eight defense modes associated with behaviors individuals display when engaged in difficult dialogues about social justice and their own privileged identities. The PIE model assumes that engaging in meaningful dialogue about race is a difficult, natural, highly variable, and necessary component of unlearning social oppression (Watt, 2007).

\section{Theoretical Framework}

Institutional theory (Scott, 2003) is enacted as the theoretical basis for this study to understand how two fraternities operated as smaller organizational units within the larger institutional context of the university setting. Institutions are systems comprised of three elements: regulative element, normative element, and cultural-cognitive element (Scott, 2003). All three elements are components that achieve meaning, stability, and 
Journal Committed to Social Change on Race and Ethnicity | 2017

order to institutions (Scott, 2003). An institutional theory lens provided a deeper and more resileient aspects of organizations and social structures (Scott, 2003).

The regulative element emphasizes rule setting, monitoring, and sanctioning in maintaining the social status of institutions (Scott, 2001; 2003). All institutions constrain and regularize behavior (Scott, 2001). Behavior in the regulative sense is governed through coercion, formalized sanctioning, or shaming (Scott, 2001). The process of establishing rules and supervising compliance influences future behavior in the organization (Scott, 2001).

The normative element emphasizes values and norms to provide a prescriptive, evaluative, and obligatory dimension into social life (Scott, 2003). Values are defined as "conceptions of the preferred or the desirable together with the construction of standards to which existing structures or behaviors can be compared and assessed" (Scott, 2001, p. 64). Norms, on the other hand, "specify how things should be done; they define legitimate means to pursue valued ends" (Scott, 2001, p. 64). Behavior in the normative element is governed through internalized social obligations and the desire to be appropriate through the eyes of other accepted members of the group (Scott, 2003).

The cultural-cognitive element revolves around shared conceptions and beliefs that are taken for granted or subconscious (Scott, 2003). Cultural-cognitive elements "emphasizes that internal interpretive processes are shaped by external cultural frameworks" (Scott, 2001, p. 67). In the cultural-cognitive, social order is maintained through collective sense-making created by the group (Scott, 2003). Symbols, like words, signs, and gestures, shape the meaning we assign to objects and activities 
Journal Committed to Social Change on Race and Ethnicity | 2017

(Scott, 2001). In other words, the shared conceptions created by institutions constitute the nature of social reality, justified simply as the ways things are done (Scott, 2001).

\section{Methods}

This study utilized a phenomenological qualitative approach to focus on understanding how group socialization shapes prejudiced views of students of color and perpetuate White supremacy through the narratives of members of two traditionally White fraternities and their experiences with race. Traditional survey research or quantitative methods often underestimate the racial ideology of White participants because of a simple dichotomy of "yes" or "no" answers (Bonilla-Silva, 2001). White racial attitudes were often depicted as tolerant or even supportive on race issues in quantitative studies; but, because of "a color-blind racial ideology pervasive in White culture" (Bonilla-Silva, 2001), qualitative research is an important and effective strategy for a more accurate analysis of Whites' racial views.

Phenomenology focuses on understanding participants' lived experiences through a phenomenon, while exploring the meaning behind those experiences (Patton, 2002). Patton (2002) identified the foundational question in phenomenology work as, "what is the meaning, structure, and essence of the lived experience of this phenomena for this person or group of people?" (p. 104). The various definitions of phenomenology all share a commitment to exploring how people make sense of their experiences (Patton, 2002).

This study examined the narratives of recently initiated fraternity members to better understand how fraternity members are socialized on race within fraternity culture. Participants were fraternity members initiated into the fraternity within the 
Journal Committed to Social Change on Race and Ethnicity | 2017

previous twelve months from the time in which this study was conducted. The research questions that guided this study were as follows:

1) How do fraternity men explain the salience of race in fraternity group socialization?

2) In what ways does Whiteness permeate group culture for college men in traditionally White fraternities?

Eight fraternity chapter leaders were contacted to participate, and two agreed to distribute the research invitation to its new members. The fraternity leaders contacted for this study, all of whom identified as White, were reluctant to participate in a qualitative study on race. Four of the fraternity leaders never returned the initial or follow up emails, and two replied, stating that they were not interested in discussing race. The two fraternity leaders who agreed to participate represented $A B C$ and $X Y Z$ fraternities.

The participants were male fraternity members from either $A B C$ or $X Y Z$ fraternity who initiated and participated in the new member education process between fall 2015 and spring 2016 as chosen through a comparison focused sampling strategy. There were seven total participants. Two additional participants from $A B C$ fraternity responded to the research invitation, but the researcher was never able to schedule an interview time that worked with their schedules. Both participants agreed to participate initially; but, after several interviews were conducted with other $A B C$ participants, they began to avoid communication and cancel meetings. There were four participants from $A B C$ fraternity and three participants from $X Y Z$ fraternity. All participants were assigned a pseudonym. This process was done to make each participant easily identifiable for the 
Journal Committed to Social Change on Race and Ethnicity | 2017

reader. The participants represented multiple ages and years in school and all identified as White (see Table 1):

Table 1. Participants

\begin{tabular}{lllll} 
Pseudonym* & Age & Year in school & Race & Fraternity \\
\hline 1) Alan & 19 & First year student & White & ABC \\
2) Ben & 20 & Sophomore & White & ABC \\
3) Chad & 18 & Freshman & White & ABC \\
4) Dave & 20 & Sophomore & White & ABC \\
5) Todd & 20 & Sophomore & White & XYZ \\
6) Victor & 19 & First year student & White & XYZ \\
7) Zach & 24 & Graduate student & White & XYZ
\end{tabular}

\section{Data Collection}

This study was conducted with two traditionally, predominantly White fraternities, which were given the pseudonyms of $A B C$ fraternity and $X Y Z$ fraternity. $A B C$ fraternity, which began the process of becoming a recognized organization in 1990, had 82 members, 76 of whom identified as White. XYZ fraternity began the process of becoming a recognized organization in Fall 2015, and has yet to receive its charter by the publication of this study. Its lack of institutional history at the research site provided the researcher with the opportunity to further explore the significance of history and tradition on organizational behavior. $\mathrm{XYZ}$ had 53 active members, 46 of whom identified as White. The chartering process for $\mathrm{XYZ}$ fraternity in Fall 2015 meant that all participants in this study were recruited by a team of full-time professional staff members from the $\mathrm{XYZ}$ fraternity headquarter office, rather than the traditional recruitment process of $A B C$ and other fraternities where current members of the chapter choose prospective members. 
Journal Committed to Social Change on Race and Ethnicity | 2017

The institutional site for the study was given a pseudonym of Southeastern University. The University website described Southeastern University as a public, nonprofit, predominantly White, land-grant institution in the southeast, founded in the later 1800's. The Carnegie Classification of Institutions of Higher Education (n.d.) further described it as a large, four-year, primarily residential, more selective, high research, doctoral granting institution with over 18,000 undergraduate students and over 4,500 graduate students. The researcher selected this site due to previously established relationships with university administrators who agreed to serve as gatekeepers, granting the researchers access to participants, data, and resources to conduct the study.

Fraternity and sorority life are an integral part of Southeastern University's campus life. Over 3,000 Southeastern students are members of a fraternity or sorority, or 23 percent of the overall student body. The Interfraternity Council (IFC) has 22 chapters. IFC is a governing board which exists on campuses with multiple social fraternities (NIC website, n.d.), typically overseeing traditionally and predominantly White fraternities. This case study required IRB approval at Southeastern University, which was granted, as well as the cooperation of the Fraternity and Sorority Life office staff for access to students, documents, and demographic data.

Data was collected using semi-structured interviews with individual participants and follow up focus group interviews for all participants from each chapter. We conducted initial individual interviews to gather baseline data from each participant. Focus groups were conducted separately for members of $A B C$ fraternity and $X Y Z$ fraternity for the collection of additional information on how each individual member 
discussed issues of race when they were around their fraternity brothers versus when they were alone with the researchers. In this situation, the focus group provided a means to see if individuals changed their reported stated opinions on race when they were around other fraternity brothers.

Interviews were conducted in a private, quiet, and comfortable space on campus, so that participants felt at ease in the environment (Glesne, 2011). All interviews were recorded using a digital recording device and transcribed by the researchers. The interviews lasted between 45 and 60 minutes. The researchers conducted one individual interview with each participant and one focus group interview for each fraternity.

\section{Data Analysis}

Data analysis for this study followed Creswell's (2014) six steps for qualitative data analysis. All interviews were transcribed verbatim, reviewed, and coded to develop a general sense of the data. Then, an emergent coding technique was used to identify key themes in the transcribed interviews. The coding process was used to generate themes for analysis (Creswell, 2014). During the coding process, the researcher made notes on printed hard copies of the interview transcripts to begin organizing potential themes. An emergent coding technique was used to identify key themes in the transcribed interviews. The comprehensive list of participant data and the researcher's observations were identified and compared to determine and allow for key themes to emerge as is consistent with qualitative data coding and analysis (Creswell \& Clark, 2007). 
Journal Committed to Social Change on Race and Ethnicity | 2017

\section{Trustworthiness}

Lincoln and Guba (1985) outlined four criteria for judging the rigor of qualitative research: (a) credibility, (b) transferability, (c) dependability, and (d) confirmability. Credibility involves establishing that the results of qualitative research are believable or credible (Lincoln \& Guba, 1985). A method used for this study to address credibility was to triangulate sources in both focus groups and individual interviews to see if conversations shifted or if the data were consistent. This data was triangulated with field notes from observations and the documents collected during data collection.

Credibility was also achieved through a process of member checking, a practice of preserving the participants' explanation of their actual experiences (Creswell, 2007). I emailed each participant a transcribed copy of the interview for their review following each interview. They were asked to review in full detail for accuracy and respond back to me with any comments or suggestions. Transferability was achieved by adequately describing the research setting and participants in the methods section of this study. Dependability was enhanced through a debriefing strategy among researchers to continually press for hidden meanings in the participants' narratives. Confirmability was achieved through the triangulation of data through various and multiple sources (Lincoln \& Guba, 1985).

\section{Findings}

Participants were asked about their experiences with race within their fraternity. All of the participants' statements were analyzed into 5 subcategories that were divided among two major themes. The two major themes from the data are (a) Regulatory Behavior and (b) the Role of Racially Segregated Environments in Perpetuating White 
Journal Committed to Social Change on Race and Ethnicity | 2017

Supremacy. Within Regulatory Behavior the subcategories were (a) levels of racism, (b) public relations, and (c) rule setting. The sub-categories under the Role of Racially Segregated Environments in Perpetuating White Supremacy were (a) (lack of) engagement with diversity, and (b) the perception that people of color are combative.

\section{Regulatory Behavior}

Participants spoke at length about attempted methods to govern fraternity members when it came to race related incidents. The participants valued the ability to address issues internally, but often had vastly different interpretations of the type of behavior that constituted regulation as compared to college or university administrators and their marginalized peers. There were three areas that impacted the students' ability to self-govern their fraternity. These subcategories were (a) levels of racism, (b) public relations, and (c) rule setting.

\section{Levels of racism}

The participants consistently spoke of racism as having at least two levels.

Participants differentiated between behaviors that they deemed as harmful, such as using racial slurs or violent behavior, and behaviors they saw as harmless, such as racial jokes or cultural appropriation which they felt members of marginalized identities should disregard. When talking about the $A B C$ fraternity culture, Alan suggested that "Nobody is really openly racist or anything like that," indicating that there may be some underlying racial bias that is not spoken of or acted on in public. Chad differentiated between levels of racism as well, stating, "I've never seen anybody get like super racist other than like a little joke." 
Chad spoke specifically about White ABC members' racial joking with one Black $A B C$ member. Chad refers to the jokes as "racist," but he delineated between joking around and the intention to cause harm. He said:

I don't know, people tell like racist one liner jokes or stuff like that. Nothing, no one will really say anything really offensive or have any ill will toward someone of a different race. I guess every now and then you'll hear a racist joke, but it's not mean spirited or anything. I wouldn't say in the fraternity that I hear that any more than I did at home or any other social situation.

However, Chad addressed the concept of racial microaggressions when he explained that he saw racism in institutional culture at Southeastern. He said, "I mean, at (Southeastern) specifically, people have been graffiti-ing (an academic building at Southeastern) a lot (with racial slurs). And if you look, like, every building is named after an old racist senator." He further added that "There's no real victim of racism in that scenario, but it's kind of messed up that every building is named after some horrible slave owner." Chad expressed an understanding that covert, subtle forms of racism can be harmful or "kind of messed up," but he did not see a victim in that scenario of racial bias.

Alan discussed the frequency of racial joking in $A B C$ fraternity culture, but he spoke of his willingness to intervene in situations where speech crossed the line. He said, "If it's in really poor taste, I would definitely say something like, 'yeah that's really messed up to say.' I mean, we joke around with each other all the time about race, religion, we always mess with each other about that kind of stuff anyways." Chad claimed the racial joking was insignificant, even admitting that students of color overheard. He said, "Whenever there's been people of a different race around, they've just taken it lightly. Nobody has ever been really mad or gotten in a fight about it. It's just 
been lighthearted. It's never been a big thing, I guess." Both Alan and Chad assumed that everyone who overheard the racial joking was accepting of it because of the lack of objection in those scenarios.

Chad reacted to a racially charged party planned by a fraternity at Southeastern University in the recent past when he stated that, "I don't necessarily think that having a party theme is a racist thing to do, but it's just that's the way it is now." Chad saw nothing wrong with the cultural appropriation from the party theme, but explained that the reactions were more of a result of political correctness. He stated, "It's like knowing the way it is now, and how like kind of liberal everyone is, it's a bad idea to do stuff like that, but I don't think it's really wrong." Ben was confused about the presence of students of color at the party. He struggled with the juxtaposition that some students of color were active in the cultural appropriation, while a larger majority denounced the party. Ben stated:

There were Black people at the party. Black people were in the pictures. They were dressed like gang members too. But then a lot of the Black community at (Southeastern) decided that that was wrong and they were literally associating themselves with gang life. Like I didn't understand it at all.

When talking about the party, some of the participants assumed the fraternity members responsible for the planning and execution of the theme meant no ill will toward students of color. The assumption that individuals had no intention to harm others with hate speech or cultural appropriation was a consistent theme in the data. Alan claimed, "It probably wasn't a smart idea to have that kind of theme for a party, but like at the same time, I doubt that it was done in what was meant to be offensive by anyone." 
The fraternity members' inability to view all racism as harmful influenced their willingness to intervene and capacity to govern this behavior internally. Some members, like Alan, were willing to intervene in situations that they perceived as crossing the line, but their view of some racism as harmless enabled them to shrug it off or laugh in situations of racial joking or cultural appropriation.

\section{Public relations}

Fraternities have a history of being portrayed negatively in the media, particularly with recent racial incidents that have made national news. The participants spoke about the need to actively address the social media of individuals within the fraternity to ensure positive public relations with both the university and the outside community. Participants expressed the desire to be portrayed positively as an influencing factor in their behavior. Participant narratives revealed the assertion that public perception on issues around race has changed, thus fraternity behavior has responded accordingly to comply with what they now considered acceptable behavior.

Participants discussed the public perception of fraternities. Chad said, "I feel like people want to make all fraternities into some White institution that's there to exclude other races and be racist, and what not." Chad went on to further claim the difficulty in addressing these behaviors. He claimed, "It's not like we're doing anything that's racist that we need to stop doing. You know what I mean? So it's kind of hard to fight that image when you really haven't done anything to deserve it."

Dave felt that it was unfair to cast all fraternities as being similar, which he felt the media did following the racist incident at Oklahoma. He said, "I'd also like to say that now in today's climate, of course it's a dumb idea to do that, but I feel like everybody 
Journal Committed to Social Change on Race and Ethnicity | 2017

tries to brand all fraternity life like they did SAE. And all SAEs are a bunch of shitheads. I don't know. That just seems wrong to me to blame everybody for that, which is pretty much what happened."

Zach stressed that fraternities are in the spotlight more than ever when talking about how $X Y Z$ regulates the public image of their fraternity, while also acknowledging the need to hold themselves to a higher standard. He spoke about utilizing the national attention fraternities receive to uphold the values of the fraternity when he said that, 'You should hold yourself to a higher standard than you know 'Johnny student' out there who him and ten of his friends can get together and throw their own racist party and nobody is ever going to find out about it."

\section{Rule setting}

Participants discussed the formal and informal ways in which they monitored and established rules for members of the fraternity regarding appropriate and inappropriate behavior.

XYZ fraternity participants talked about a formal process established within their organization to deal with violations of the fraternity code of conduct. Todd, in particular, described this process as he has direct involvement as a leader of the fraternity.

Todd discussed how an issue would be regulated in XYZ fraternity when he stated, "I think everyone, especially at (Southeastern), is realizing how fast a ship can sink. I think a lot more people are taking these matters a lot more seriously." He further clarified that individuals accused of racial bias within the fraternity would go through the XYZ judicial board process. 
Todd equated the lack of bias incident reporting and the strong synergy he saw among members as a sign that $\mathrm{XYZ}$ was building an inclusive culture:

We've never had anything reported where they felt uncomfortable from another member of the fraternity. And from what I can tell from a leadership standpoint, I think everyone has meshed together as one big brotherhood, I don't think they're being isolated out or anything like that.

Participants in $\mathrm{ABC}$ fraternity spoke of a more informal process for sanctioning member behavior. Several participants found it hard to believe that racial bias could come from within $A B C$ fraternity, but insisted that the membership would punish someone who committed an incident by removing him from the fraternity. Alan said, "If something actually happened, and one guy actually did something then we would (remove him) and get him out of here. That's what I would do, personally." Ben explained that individual members check each other in certain cases. He explained a situation where a member repeated a racial slur that his grandfather used to say. "He just said an old saying that he grew up hearing. Somebody didn't see where he was coming from, and somebody said, you can't be saying that dude."

The institutions' willingness to sanction racial incidents and bias was an element that several participants talked about as an influencing factor for their own internal policing of behavior. Chad described that when he said that, "(Southeastern) especially is cracking down on Greek life for everything, so we just have to just be really careful and not do anything stupid." He mentioned the self-interest involved in avoiding racially suggestive themes, even if he did not necessarily agree. Chad stated, "People look at everything as like targeting another race, and you just have to be really careful. Like just looking out for yourself. So yeah, I don't know, I would try to steer clear of any racial overtones in a party theme, I guess." 
Journal Committed to Social Change on Race and Ethnicity | 2017

Participants were hesitant when talking about the use of "force" to regulate behavior. $\mathrm{XYZ}$ fraternity participants were at a loss when discussing how to improve race relations within their fraternity. Victor claimed, “I don't know a way to make a rule or make a system that changes that without doing something that's going to negatively impact the organic, natural way that people form relationships." Chad opposed any training, education, or discussion on race, saying, “I don't know, it hasn't really been a problem, I guess."

The Role of Racially Segregated Environments in Perpetuating White Supremacy

Both $A B C$ and $X Y Z$ fraternities operated as racially segregated environments. The existence of the organizations as predominantly White institutions led to the portrayal of people of color in a largely negative light through stereotypes that went unchecked. Under this theme, the areas of (a) (lack of) engagement with diversity, and (b) the perception that people of color are combative are explored.

\section{(Lack of) Engagement with diversity}

The lack of racial diversity in $A B C$ and $X Y Z$ fraternity membership led participants to recall limited opportunities to discuss race with other members. Ben of $A B C$ fraternity stated that, "For us, it never really comes up like that often, as a brotherhood, and l've never really sat down and talked with everybody about race before." Dave also indicated that conversations about race do not typically occur. He explained, “Um, I don't know. It's something that's not really brought up a lot." Victor suggested that recent current events at Southeastern were the primary reason that brothers of $\mathrm{XYZ}$ fraternity were having conversations about how race impacted their fraternity. When asked if conversations about race come up often, Victor responded, "I 
would say that the discussion yesterday was the first time that people have talked for a prolonged time about anything having to do with race," referring to a conversation in which $\mathrm{XYZ}$ brothers informally discussed the protests at Southeastern the day before.

The $A B C$ fraternity participants became animated when we discussed the current protests at Southeastern University. They explained how they withdrew even more from interacting with people of other races because of their perception of the current events. Dave said, "I think it's partly because of things like this (the current protests), people are scared to even..." Ben jumped in and finished his sentence, "to move those cultural boundaries?" Dave finished by saying, "Yeah. I think that everybody is scared that they're going to get in trouble in some way, get kicked off campus, like they just don't want to have anything to do with it."

Participants discussed the notion that discussing race as a White identified student can be uncomfortable. When asked if he was uncomfortable discussing race, Dave of ABC fraternity responded, "Yeah, I guess. I don't really like to get in the whole Ferguson topics or stuff like that. Yeah." Chad explained the reason he does not engage in discussions on race, saying, "I don't find it necessarily uncomfortable, but I don't think I'm a very, I guess, informed person about it."

Todd described conversations about race in $\mathrm{XYZ}$ fraternity as occurring very naturally in informal settings. Todd stated, "Casually, I think everyone is pretty comfortable talking with one another about those subjects." Victor of XYZ fraternity countered that conversations about race do not come up, but he felt that it was not because people are uncomfortable, but because race is often not a salient part of White identity, "I think it just honestly doesn't occur to people." 
Journal Committed to Social Change on Race and Ethnicity | 2017

Zach explained that a lack of knowledge around race related issues is the main reason for the frequency of these events, "Racism to most of my brothers is like saying the $\mathrm{N}$ word or like blatantly saying I hate Black people. The ideas of microaggressions or anything like that is not even anywhere on the radar for most White fraternity men." Zach suggested that increasing the number of underrepresented populations in traditionally, predominantly White fraternities would serve as a helpful solution toward encouraging privileged identities to engage with difference. When talking about privileged identities, Zach claimed, "I think they're not even being challenged to think on systems that exist in our society or how they are benefitting or not because they're all people that are in majority identities, most of the time. I really do think getting members or people who can share their stories with them and have sustained time around them is really important."

The lack of any experience with people of different races, can be problematic for White identified individuals who draw narrow conclusions about people of color based on stereotypical views. Dave discussed how his few interactions with people of color in high school gave him a negative impression of Black students in particular, but students of color at Southeastern University "opened (his) eyes" and "broadened (his) sense of acceptance." Zach articulated a more direct and self-rewarding benefit to interacting with diverse individuals. He claimed, "Good luck getting a job nowadays where they don't ask you one diversity question."

Zach expressed disappointment in the lack of interest displayed by XYZ fraternity members in learning more about him and his intersection of identities. He explained that a celebration of diversity would change the culture of the fraternity. Zach stated: 
That's what I think would change the culture is if we did celebrate diversity and talk about it and engage in a conversation. You know l've engaged in a couple of passive conversations when l've come out to people in the group at first, but I'm sure at this point everyone knows, and no one has taken any interest in talking with me about who I am as a human. So sometimes that feels a little crappy but I don't think, I don't know why that is, but it is what it is.

Participants in both $A B C$ and $X Y Z$ fraternities expressed that they were interested in engaging in difference in the future, but several were hesitant. Alan expressed that he would be hesitant to interact with a historically Black fraternity or sorority. He feared, "I think there would be some kind of racial tension going on there."

\section{Perception that people of color are combative}

The notion that people of color were combative, particularly around issues of race, was a consistent theme with $A B C$ fraternity participants. Dave spoke about his experiences with race when a race related incident occurs nationally:

There's just a big division in terms of everybody is friendly to each other, but then something controversial happens like somebody gets shot and it's just like this whole big thing. I don't know. I try to stay out of it as much as I can. Honestly, not a big fan of it.

$A B C$ fraternity participants used current events at Southeastern as an opportunity to reflect on race. When talking about the gang themed party at Southeastern, Ben felt that students of color were aggressive in addressing the cultural appropriation from the party. He explained, "The day after the party, (the Southeastern fraternity that planned the party) got called to a dialogue with like 200 Black students and I was talking to guys who had to go and they literally walked in there and started getting berated." Ben went on to explain his thoughts, "I just thought it was ironic that there was an uproar about it. I just felt like it's very opposite of their cause. I felt like they're more equating the Black 
Journal Committed to Social Change on Race and Ethnicity | 2017

community with gangs than denouncing gangs as part of the Black community. I don't know."

$A B C$ fraternity participants had several things to say about a recent protest on campus at Southeastern in response to a racist incident that occurred. Student activists held a sit-in and protest following the incident, which occurred on campus during the time that our focus group interview was held, so it provided an additional opportunity to reflect on race with the participants. Ben provided a conspiracy theory about the incident. Ben suggested, "I heard it was an African American student who did that (committed the racist incident) to raise racial awareness to make this a thing." Alan backed him up saying he heard the same thing. He then added that, "This (Southeastern building sit-in) campout was planned even before that. This is just what l've heard."

Other ABC participants had strong feelings about the demands made by students upset about the racial climate on campus. Chad said, "And that whole protest is basically asking for segregation again. Like they want like their own multicultural building, they want the school to specifically hire Black professors, everything they're asking for is...Ben finished his sentence saying, "Very racially oriented rather than about equality." Chad admitted "Yeah, it's not about equality, it's about them wanting things because they're mad. I don't get it."

Alan questioned the unfair treatment that marginalized students at Southeastern receive when he explained that "Yeah, and I obviously can't speak to this because I'm not a Black student at (Southeastern), but I don't see any student coming here and getting unfair treatment, from the school at least." 
Journal Committed to Social Change on Race and Ethnicity | 2017

Some $A B C$ fraternity participants were also quick to deflect blame when talking about their recruitment of students of color. Chad suggested that history could be at play when he explained the lack of students of color in predominantly, traditionally White fraternities "I think they're intimidated in some ways." Alan immediately countered that he thought students of color are to blame for that. Alan said, "Intimidation is something having to do more with them than us. Like they maybe think that we don't want more Black kids, but I would totally be open to any Black kid if he was cool and seemed like he fit into the fraternity. Regardless."

The findings presented narratives on race and the fraternity experience as described by the seven participants. The participants described race as not being a salient part of their experience, but described myriad of ways that Whiteness permeated their group culture in a traditionally, predominantly White fraternity.

\section{Discussion}

$A B C$ participants' continued mentioning of "open racism" and racism that is not "mean spirited" suggests that there was an underlying culture of racism that was intended to remain covert. One way in which participants described this covert culture of racism was in their descriptions of racial joking told in homogenous White settings. The findings from this study are consistent with Cabrera's (2014a) results on racial joking. Racial jokes were not seen as harmful by White participants because they were told in White racial enclaves that reinforced the normalcy of Whiteness. Few White peers described racial jokes as racist, therefore participants rationalized the behavior as innocuous and framed people of color as unreasonable in situations where they spoke out about jokes, cultural appropriation, or racial hate speech on campus. The results 
Journal Committed to Social Change on Race and Ethnicity | 2017

from this study suggest that naming racism, both overt and covert, is helpful toward educating White men on the harm caused by covert forms of racism regardless of intent.

The participants were insulated within White spaces making it difficult for them to see evidence of racism and allowing their views on race to go largely unchallenged. When confronted with evidence of racism at Southeastern, participants deflected blame toward students of color at the institution, claiming they were actually at fault for the tense racial environment on campus. This finding is consistent with Watt's privileged identities model that explains individuals in the deflection defense often refuse to acknowledge the reality of injustice or oppression, instead deflecting blame onto others (Watt, 2007).

White students in predominantly White spaces have few opportunities to change negative stereotypical views of students of color because of a lack of engagement and limited interactions with people of races other than White. Dave expressed how his feelings changed after he was exposed to more students of color when he came to Southeastern. However, it is problematic that many White students in traditionally, predominantly White fraternities limit the number of opportunities they have to interact with students of color because of the insulated and hegemonic White spaces within the IFC fraternity system. This study highlighted the need for further research on the covert and hidden meanings of fit enacted by "color-blind" White fraternity men during the fraternity recruitment process to restrict access to only those students of color who are "passing" as White or have the economic means to counter-balance other differences. 
Participants recognized that race is a more salient topic for students of color than it is for them or their White peers. Participants, all of whom identified as White, did not indicate that diversity was something they sought in fraternity membership. Despite the homogenous nature of their fraternity membership, some participants mentioned their perception that Black students care more about connecting with other Black students than White students care about associating with only White students. Participants described race as a non-issue within their college and fraternity experience, but spoke about students of color on campus as making everything "racially oriented." This study highlighted the need for institutions to determine ways to articulate racist incidents involving one fraternity to the entire fraternity and sorority community to broaden the education beyond a punitive measure against the offender. It is also important to note the negative implications of using students of color to educate mostly White fraternity men on racism, as many of the participants in this study perceived students of color at Southeastern to be combative because the university put them in the difficult position of explaining the impact of racism to their peers.

Zach explained that his $\mathrm{XYZ}$ fraternity brothers reduced conversations and topics down to being only about race. The lack of interaction with students of color and the avoidance of conversations about race led participants to possess very simplistic and stereotypical views of race. For example, Zach described that students would talk about an historically Black fraternity as "oh, that's the Black fraternity, right?" or would discuss a social event planned or attended by a group of Black students as "that's a Black party." 
It is worth noting that while the authors continually used the term, student of color, to identify any student who did not identify as White to encompass a variety of racial identities, participants consistently referred to a Black or White binary in their language. Participants only discussed Black students when talking about non-White fraternity brothers despite the fact that both fraternities in the study had students identifying as a race or ethnicity other than Black. This suggests a limited understanding of multiculturalism and the complexity of racial identities.

The narratives reflected a number of societal factors influencing Southeastern's racially segregated fraternity environments including the history and tradition of traditionally White fraternities, the region in which the study took place, and the institutional culture. The results revealed that members of two different fraternities constructed different meanings about race, suggesting that culture can affect the influence of Whiteness on individuals within an institution, even influencing different institutions under the same campus culture. Outside factors shaped participants' willingness to transcend cultural boundaries. The segregation the participants viewed outside of the college environment made racial segregation seem natural within, as they followed patterns they observed elsewhere. Participants were hesitant to bring up inclusivity or diversity in many settings because of the politicized nature of those words, and the perceived backlash they would receive from other fraternity members for even broaching the topic. Alumni and advisors have to help facilitate a culture where talking about inclusivity does not carry with it a negative connotation.

Of perhaps even greater importance as talking about the participants is discussing those who chose not to participate. Eight fraternities were contacted and 
declined to participate prior to finding $A B C$ and $X Y Z$ fraternities. Furthermore, two $A B C$ fraternity members who originally chose to participate opted out of the study, assumedly after learning more about the nature of the conversations from other participants. Perhaps the two non-participants were fearful of what they might reveal about their racial attitudes. Perhaps they had nothing to say about race at all. Regardless of the reasoning, the inherent privilege in the ability to avoid discussions of race and the resistance by some White students at Southeastern to engage in this work should be noted.

Recent racial tension and current protests at Southeastern created opportunities for White students to speak openly about race and racism. Participants outlined having conversations about race and racial issues, some for the first time in their lives, among fraternity members because it was a timely topic. This sudden willingness to discuss race speaks to the salience of race for many White college students' identities. White students lack awareness of racial tensions and conflict (Ancis, Sedlacek, and Mohr, 2000) until the campus climate has become so balkanized that they are forced to take notice.

\section{Implications for Practice}

The findings from this study suggested that incidents involving racial bias were typically governed informally by fraternity members. Participants in $A B C$ fraternity described a culture of racial joking that was regulated by members who would intervene if jokes were in "really poor taste." The notion that racial joking and stereotyping of people of color occurs tastefully and in good fun perpetuates a harmful environment, leaving little room for students of any race to question or push back on those 
Journal Committed to Social Change on Race and Ethnicity | 2017

established norms. Bystander intervention programs are needed to address the toxic environment created in these settings, and specifically that quiet participation in racial joking provides a tacit approval and is still considered racist behavior.

White fraternity leaders responsible for accountability measures saw little evidence of racism within their predominantly White fraternity spaces. The inability to recognize racial microaggressions or covert or subtle forms of racism make the typical White fraternity leader a poor choice to lead regulative functions of the fraternity when racial issues arise. Both $A B C$ and $X Y Z$ fraternities lacked an outlet for students to report issues of racial bias or racial incidents. Without a formal mechanism to report bias, fraternity leaders assumed that all members were having a positive experience. The regulative element of institutional theory provides a better understanding of how institutional rule setting, monitoring, and sanctioning behavior influences future behavior. Colleges and universities need formal mechanisms and processes in place to address and intervene in issues of racial bias or violence both at a macro and micro level to assist student organizations and their members in regulation.

Participants discussed the implications of being labeled as racist in the context of the level of oversight provided by university administrators. The university's willingness to regulate racial bias or incidents regarding race was influential in the participants' response to these matters. Participants spoke about the need to avoid racial overtones in their party themes, for example, because of previous sanctions enacted on another fraternity by the university indicating how institutional culture informed their behavior. Participants in XYZ fraternity talked about shaming (and ultimately sanctioning) the new member who was removed from the fraternity for racist behaviors because they knew 
that his actions were a reflection of their fraternity. The recent string of racist incidents by fraternities at Southeastern University and nationwide influenced behavior in both $A B C$ and $X Y Z$ fraternities. Participants discussed the ways in which they monitored members' social media accounts and the public image of their fraternities because they were well aware of the current racial climate and had seen firsthand the implications for misbehavior. While it is ultimately desirable to move beyond punitive measures, this study highlights an opportunity to use regulative functions to inform behavior where little understanding or empathy is developed currently.

Participants found no evidence of racism in the cultural appropriation found within fraternity party themes at Southeastern University and other institutions in recent history. There was an assumption from participants that racist actions by White fraternity men were mostly unintentional and executed with no ill will. The findings of this research underscore the importance of the intention of racist actions on the interpretation of the action by White men. In terms of accountability, the culture perpetuated by fraternity members is one of avoidance when it comes to racial issues, with no clear desire for education about why something might be offensive or what fraternities can do to create inclusive environments. The participants' opposition to cultural competence training and education was because they did not observe a problem with racism within their own experience. Advisors, college and university staff, and fraternity headquarter staff must be diligent in naming the racism in our institutions to provide concrete examples of where there has been a history of racism in traditionally and predominantly White fraternity communities. 
Journal Committed to Social Change on Race and Ethnicity | 2017

Institutional messages regarding inclusion and intolerance of racial incidents are impactful measures toward establishing campus culture. The ways in which institutions respond, particularly to student activism around equity and inclusion, frame the way that students and student organizations make sense of their environments. What university administrators say or do not say in these situations can have a huge effect on student perception and action.

The fraternity education process was devoid of any stated commitment to diversity and inclusion. The fraternity values, ideals, and teachings during the new member education processes for both fraternities focused on respect and teaching behaviors synonymous with being a gentleman, but like other aspects of fraternity culture, the teachings refrained from addressing race or diversity directly. Participants expressed no desire to change the education requirements to reflect a growing need for educating diverse citizens. However, the results from this study suggest that additional training, education, and dialogue is needed for White students to understand more on racial microaggressions and cultural appropriation. Cabrera (2014a) advocated for structured dialogue and space to critically unpack Whiteness. University administrators should consider engaging White students in dialogue and programs aimed at the critical deconstruction of Whiteness and White privilege, particularly when race is being discussed on campus because of campus-wide or national events. Furthermore, national and international fraternity headquarters should be clear about their racial histories and their commitment to diversity and inclusion moving forward. Combatting a long history of oppression takes years of dismantling structures and embedded 
Journal Committed to Social Change on Race and Ethnicity | 2017

processes, and fraternity headquarter staff and alumni must be diligent about making racial consciousness and inclusivity a priority for the organization.

This study added to the body of research on the construction and maintenance of positive group dynamics as the primary goal of fraternity membership. Both fraternities strived for loyalty and synergy among group members above all else. Fraternity headquarter staff must help undergraduate fraternity members celebrate difference of experiences and opinion through stated commitments to inclusive excellence. The participants in this study had difficulty differentiating between a positive experience and the desire to remain silent about a negative one. Fraternities must determine ways to build positive group dynamics without prioritizing blind loyalty for groupthink. Speaking out against racial bias and racism does not imply a betrayal against the fraternity, and our fraternities must reinforce the positives that come from calling out destructive and harmful behaviors.

The findings make clear that there is significant work left to disrupt hegemonic Whiteness, but there were promising examples of interrupting racist culture. Ben described an instance within $A B C$ fraternity of a member asserting that "you can't be saying that dude" to another member who used a racial slur. Zach frequently challenged XYZ brothers to disrupt oppressive structures. Harris and Harper (2014) referred to this bystander intervention as "calling brothers out" when fraternity members enacted productive performances of masculinity by challenging behaviors they viewed as sexist, homophobic, or racist. Student Affairs practitioners must find ways to encourage fraternity members in "calling brothers out" to champion a culture of challenging negative behaviors in the moment, regardless of racist intent. It is paramount to 
acknowledge the meaning placed on peer perception by the participants when talking about whether or not to intervene. The importance of surrounding well-intentioned White fraternity men with positive influences such as like-minded student leaders, faculty and staff, and positive advisors cannot be overstated in creating a positive culture of intervention.

\section{Conclusion}

It is clear that race and racism, like discussing religion and politics at the dinner table, are still topics that many White Americans find uncomfortable to approach. Participants stated that the only conversations they ever had with fraternity brothers about race were because of the recent racial incidents and protests at Southeastern. In an increasingly diverse world, that should not be the case. This study suggests that campus and national race incidents are an ideal time to engage White students in dialogue on race that can potentially interrupt the perpetuation of Whiteness.

This study adds to our understanding of the socialization of Whiteness and therefore helps to dismantle oppressive structures. National and international fraternities must acknowledge the ugly history of oppression and racism of traditionally and predominantly White fraternities and develop public and espoused commitments to inclusive excellence. Fraternities must be creative in shifting the construction of positive group dynamics from one prioritizing blind allegiance to the group to one where a culture of calling out bad behavior becomes entrenched into the fabric of contributing to establishing true brotherhood.

\section{References}


Journal Committed to Social Change on Race and Ethnicity | 2017

Associated Press (2015, March 15). Timeline: List of recent sorority and fraternity racist incidents. USA TODAY College. Retrieved on August 11, 2015 from http://college.usatoday.com/2015/03/15/timeline-list-of-recent-sorority-andfraternity-racist-incidents/

Barone, R. (2014). White clauses in two historically white fraternities: documenting the past and exploring future implications. Oracle: The Research Journal of the Association of Fraternity/Sorority Advisors, 9(1), 54-73.

Bonilla-Silva, E. (2001). White supremacy and racism in the post-civil rights era. Boulder, CO: Lynne Rienner Publishers.

Cabrera, N. L. (2012). Working through whiteness: White, male college students challenging racism. The Review of Higher Education, 35 (3), 375-401. doi: 10.1353/rhe.2012.0020.

Cabrera, N. L. (2014a). But we're not laughing: White male college students' racial joking and what this says about "post-racial" discourse. Journal of College Student Development, 55(1), 1-15. doi: 10.1353/csd.2014.0007.

Cabrera, N. L. (201b). Exposing whiteness in higher education: White male college students minimizing racism, claiming victimization, and recreating white supremacy. Race Ethnicity and Education, 17(1), 30-55. doi:10.1080/13613324.2012.725040.

Cabrera, A. F., \& Nora, A. (1994). College Students' Perceptions of Prejudice and Discrimination and Their Feelings of Alienation: A Construct Validation Approach 1. The Review of Education, Pedagogy, and Cultural Studies, 16(3-4), 387-409. doi: 10.1080/1071441940160310

Creswell, J. W. (2014) Research design: Qualitative, quantitative, and mixed methods approaches. Sage Publications: Los Angeles, CA.

Creswell, J. W., \& Clark, V. L. P. (2007). Designing and conducting mixed methods research. Sage Publications: Thousand Oaks, CA.

Crocker, J., \& Major, B. (1989). Social stigma and self-esteem: The self-protective properties of stigma. Psychological Review, 96, 608-630.

Glesne, C. (2011). Becoming Qualitative Researchers: An Introduction. Pearson Education: Boston, MA.

Harper, S. R., \& Hurtado, S. (2007). Nine themes in campus racial climates and implications for institutional transformation. New Directions for Student Services, 2007(120), 7-24. doi: 10.1002/ss.254

Harris, C. I. (1993). Whiteness as property. Harvard Law Review, 106(8), 1707-1791.

Hughey, M. W. (2010). A paradox of participation: Nonwhites in white sororities and fraternities. Society for the Study of Social Problems, 57(4), 653-679. doi: 10.1525/sp.2010.57.4.653

Hurtado, S. (1992). The campus racial climate: Contexts of conflict. The Journal of Higher Education, 63(5), 539-569.

Hurtado, S., Milem, J., Clayton-Pedersen, A., \& Allen, W. (1999). Enacting Diverse Learning Environments: Improving the Climate for Racial/Ethnic Diversity in Higher Education. ASHE-ERIC Higher Education Report, Vol. 26, No. 8. ERIC Clearinghouse on Higher Education, One Dupont Circle, NW, Suite 630, Washington, DC 20036-1181. 
Lincoln, Y. S., \& Guba, E. G. (1985). Naturalistic inquiry (Vol. 75). Newbury Park, CA: Sage Publications.

Morgan, D. L., Zimmerman, H. B., Terrell, T. N., \& Marcotte, B. A. (2015). "Stick With Yourselves; It's What's Normal”: The Intergroup Racial Attitudes of Senior, White, Fraternity Men. Journal of College and Character, 16(2), 103-119.

Muir, D. E. (1991). "White" fraternity and sorority attitudes toward "blacks" on a deep south campus. Sociological Spectrum, 11(1), 93-103. doi:10.1080/02732173.1991.9981956.

NIC website (n.d.). North-American Interfraternity Conference homepage. Retrieved December 15, 2017 from http://nicindy.org

Park, J. J. (2014). Clubs and the campus racial climate: Student organizations and interracial friendship in college. Journal of College Student Development, 55(7), 641-660. doi: 10.1353/csd.2014.0076.

Pascarella, E. T., Edison, M., Nora, A., Hagedorn, L.S., \& Terenzini, P. T. (1996). Influences on students' openness to diversity and challenge in the first year of college. Journal of Higher Education, 67(2), 174-195. doi: 10.2307/2943979.

Patton, M. Q. (2002). Qualitative Research \& Evaluation Methods. Sage publications: Thousand Oaks, California.

Patton, T. O. (2008). Jim crow on fraternity row: A study of the phenomenon of blackface in the White southern fraternal order. Visual Communication Quarterly, 15(3), 150-168. doi: 10.1080/15551390802235503.

Picca, L., \& Feagin, J. (2007). Two-faced racism: Whites in the backstage and frontstage. New York, NY: Routledge.

Rankin, S. R., \& Reason, R. D. (2005). Differing perceptions: How students of color and White students perceive campus climate for underrepresented groups. Journal of College Student Development, 46(1), 43-61.

Reason, R. D., \& Evans, N. J. (2007). The complicated realities of Whiteness: From color blind to racially cognizant. In New Directions for Student Services (pp 67-75). San Francisco, CA: Jossey-Bass Publishers.

Schnoebelen, A. (2013, January 9). College enrollment will grow more slowly, education department projects. The Chronicle of Higher Education. Retrieved April 15, 2015, from http://chronicle.com/article/College-Enrollment-Will-Grow/136547/

Scott, W. R. (2001). Institutions and Organizations. Thousand Oaks, CA: Sage Publications.

Scott, W. R. (2003). Institutional carriers: Reviewing modes of transporting ideas over time and space and considering their consequences. Industrial and corporate change, 12(4), 879-894.

Sidanius, J., Van Larr, C. V., Levin, S., \& Sinclair, S. (2004). Ethnicity and the dynamics of social identity on the college campus: The good, the bad, and the ugly. Journal of Personality and Social Psychology, 87, 96110.

Solorzano, D., Ceja, M., \& Yosso, T. (2000). Critical race theory, racial microaggressions, and campus racial climate: The experiences of African American college students. Journal of Negro Education, 69(1), 60-73.

Syrett, N. L. (2009). The company he keeps. The University of North Carolina, USA Press. 
Journal Committed to Social Change on Race and Ethnicity | 2017

The Carnegie Classification of Institutions of Higher Education (n.d.). About Carnegie Classification. Retrieved December 15, 2017 from http://carnegieclassifications.iu.edu/2010/

Van Dyke, N., \& Tester, G. (2014). Dangerous climates: Factors associated with variation in racist hate crimes on college campuses. Journal of Contemporary Criminal Justice, 30(3), 290-309. doi: 10.1177/1043986214536666

Watt, S. K. (2007). Difficult dialogues, privilege, and social justice: Uses of the privileged identity exploration (PIE) model in student affairs practice. The College Student Affairs Journal, 26(2), 114-126. http://files.eric.ed.gov/fulltext/EJ899385.pdf. 